\title{
INFLUENCE OF CRITICAL SUCCESS FACTORS IN THE PERFORMANCE OF INFRASTRUCTURE PROJECTS IN QATAR
}

\author{
Maryam Hussain Abal-Seqan \\ Supervisors: Dr. Khalid K. Naji, Dr. Shaligram Pokharel \\ College of Engineering - Qatar University
}

Spring 2021

\section{Abstract}

This thesis focuses on developing an understanding of factors that can help in increasing the project performance in Qatar and elsewhere. The understanding leads to the focus on factors in the design, development and operation of the project. This thesis identifies 23 critical success factors in four different groups: top management support, project manager's skills, project team's skills, and stakeholder management knowledge. The thesis also identifies four main project success criteria: project delivery on time, within the budget, with expected quality, and meeting stakeholder's satisfaction.

\section{Novelty in Thesis}

1. The development of the relation between the project performance and the critical success factor is done for the first time in Qatar. The thesis tests 23 hypothesis on the impact of critical factors in the successful completion of the project in Qatar and 10 hypothesis on the relation between the knowledge of the project manager and the project performance.

2. The thesis also develops the difference in the perception on factors related to project success and knowledge related to project performance.

\section{Introduction}

It is important to understand the factors and project performance related to the projects and they are collectively provided in (Bekr, 2017), (Niagara \& Datche, 2015), (Ibrahim, 2019) and (Khamaksorn, 2018). Based on the focus of the thesis, the following two objectives and two research questions are discussed in this thesis:

1- To identify the key success factors and criteria in construction projects, especially in the government sector in Qatar.

2- To evaluate the relationship between project performance and application of project knowledge areas.

Research Questions:

RQ1: What are the most important factors that contribute to the success of projects?

RQ2: What are the critical project knowledge areas that affect construction project performance?

\begin{tabular}{|c|} 
Methodology \\
\hline Formulation of research objectives and research \\
questions
\end{tabular}

\section{Literature Review}

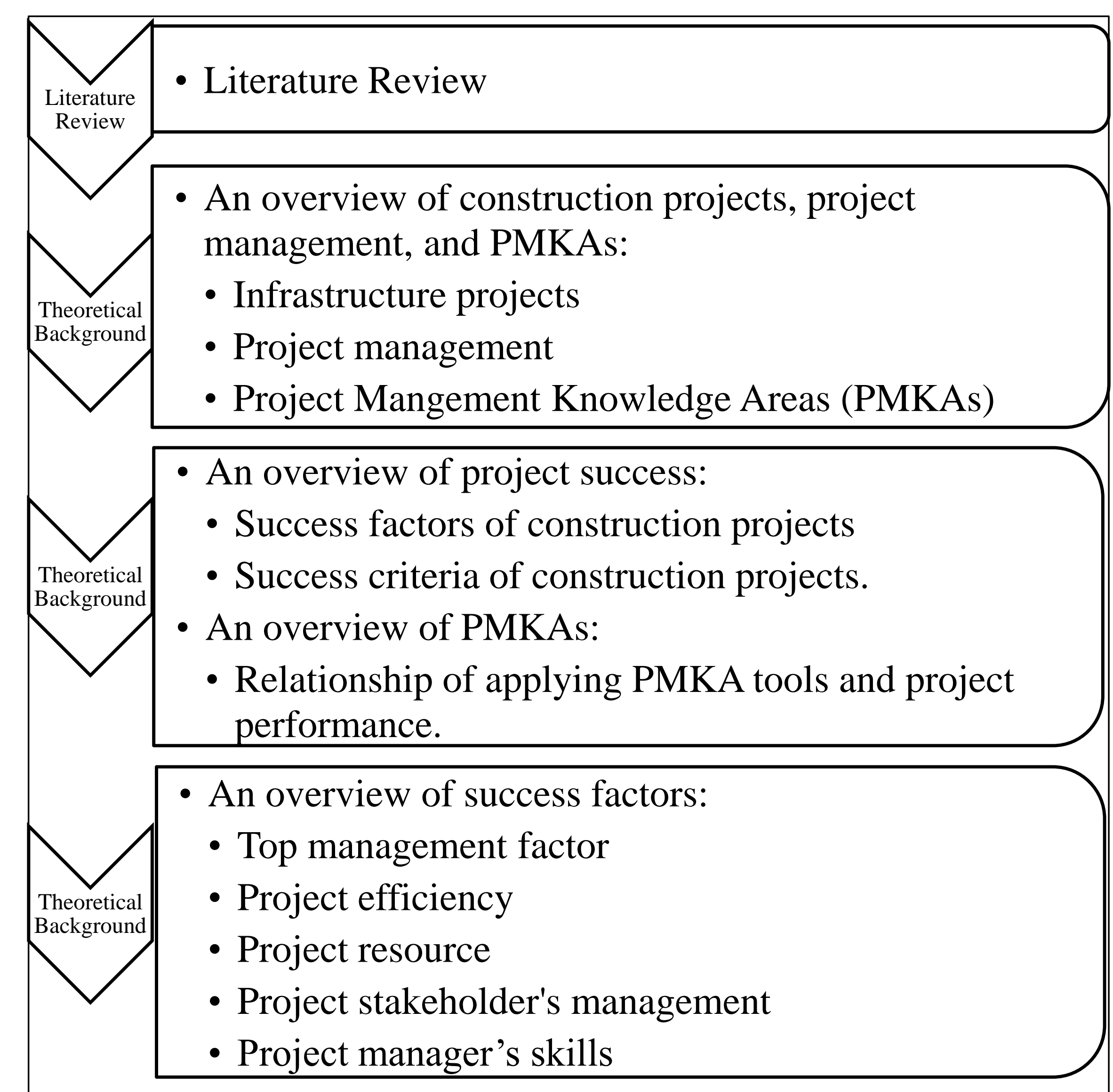

Figure 2. Structure of the literature review

\section{Research Framework}

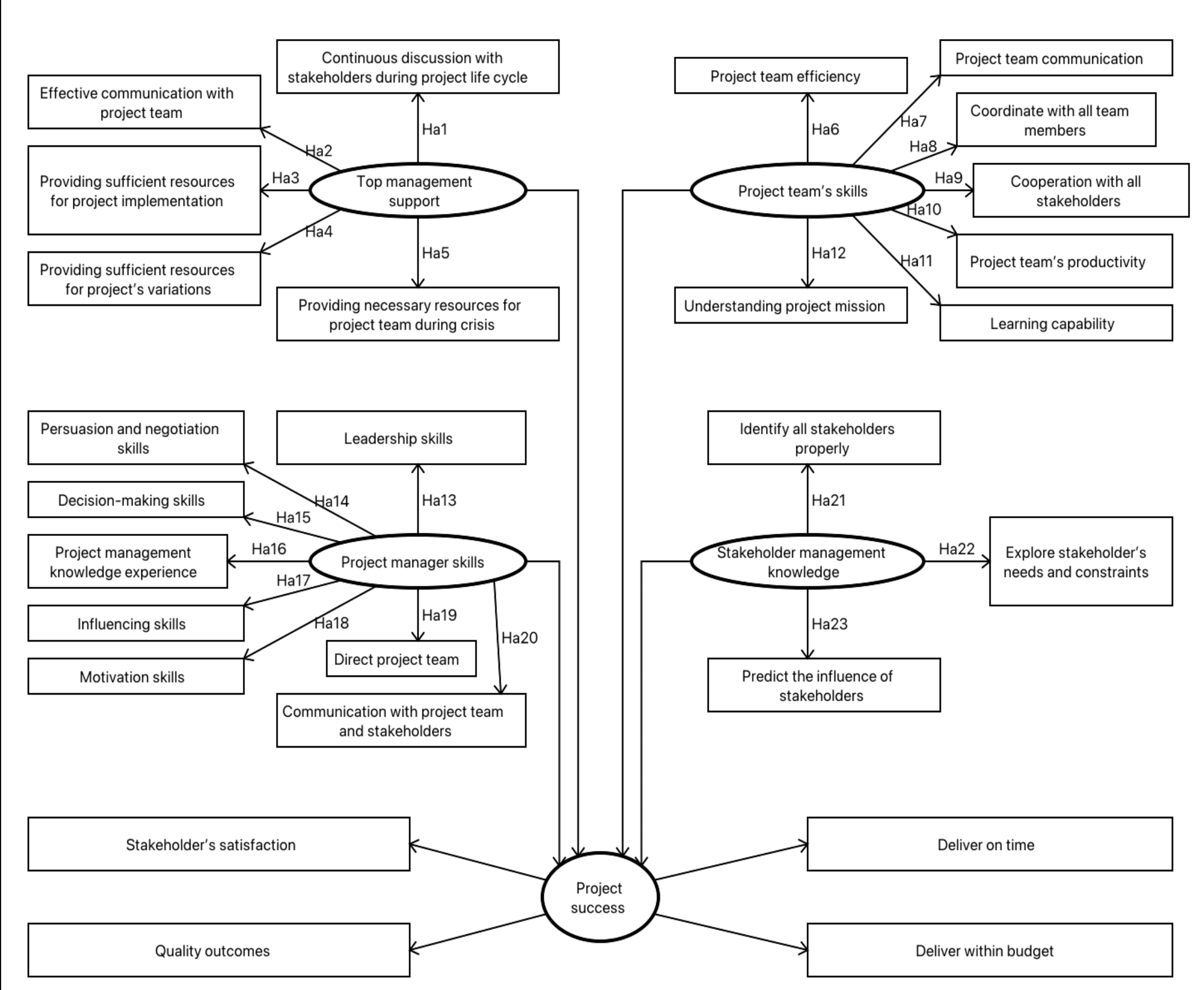

Figure 3. Part A - Conceptual framework model for the developed hypotheses related to success factors.

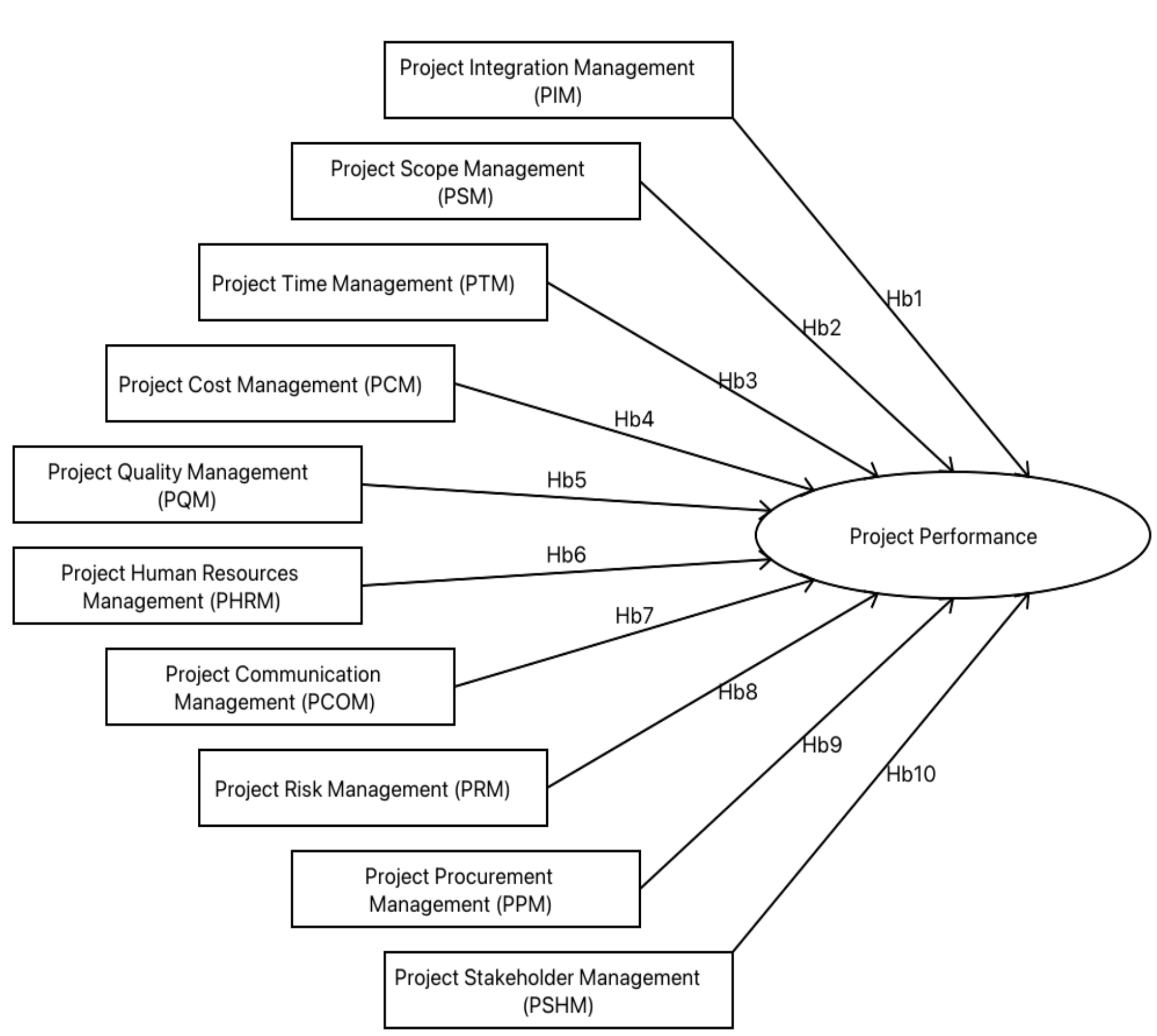

Figure 4. Part B - Conceptual framework model for the developed hypotheses related to PMKAs.

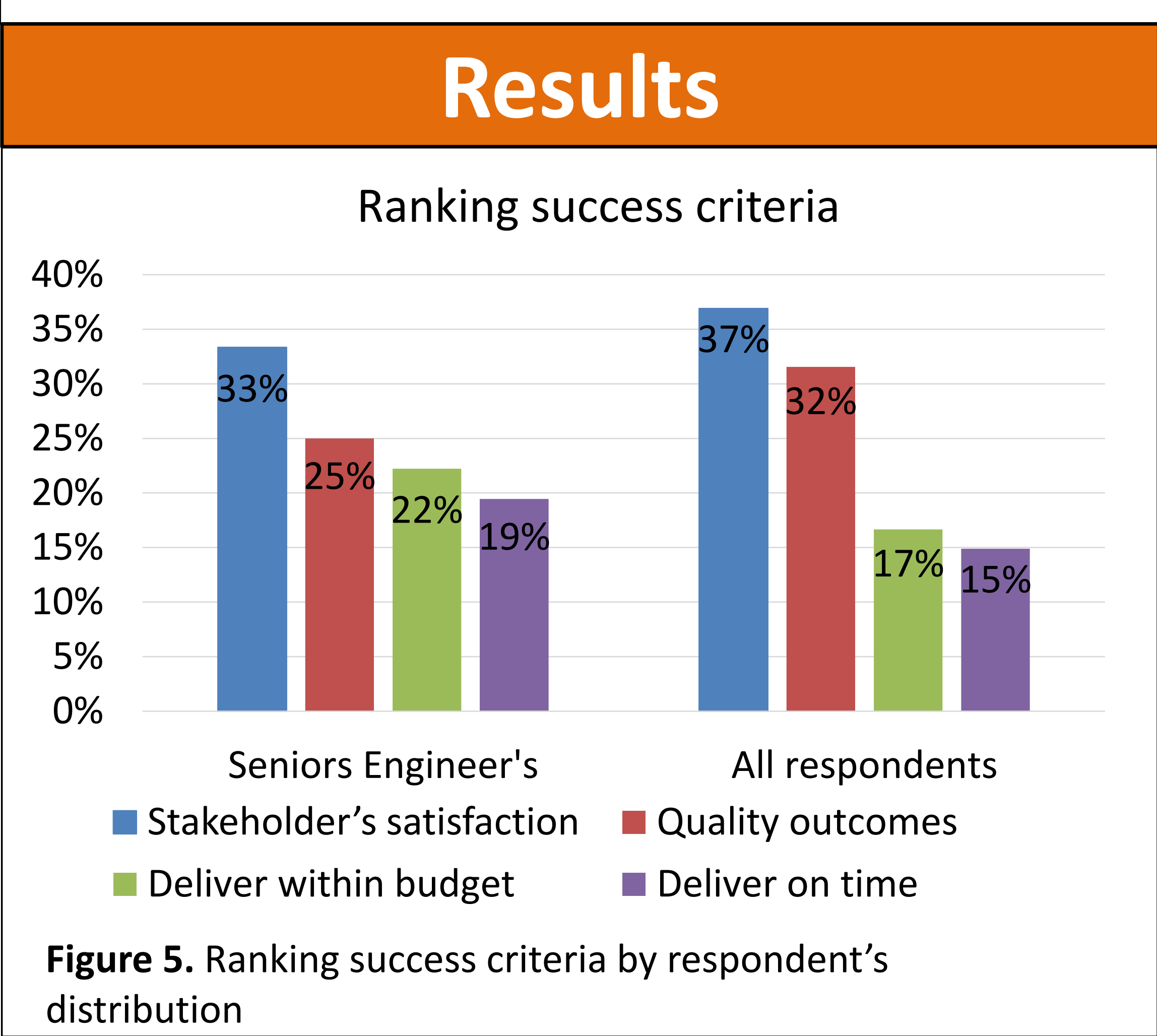

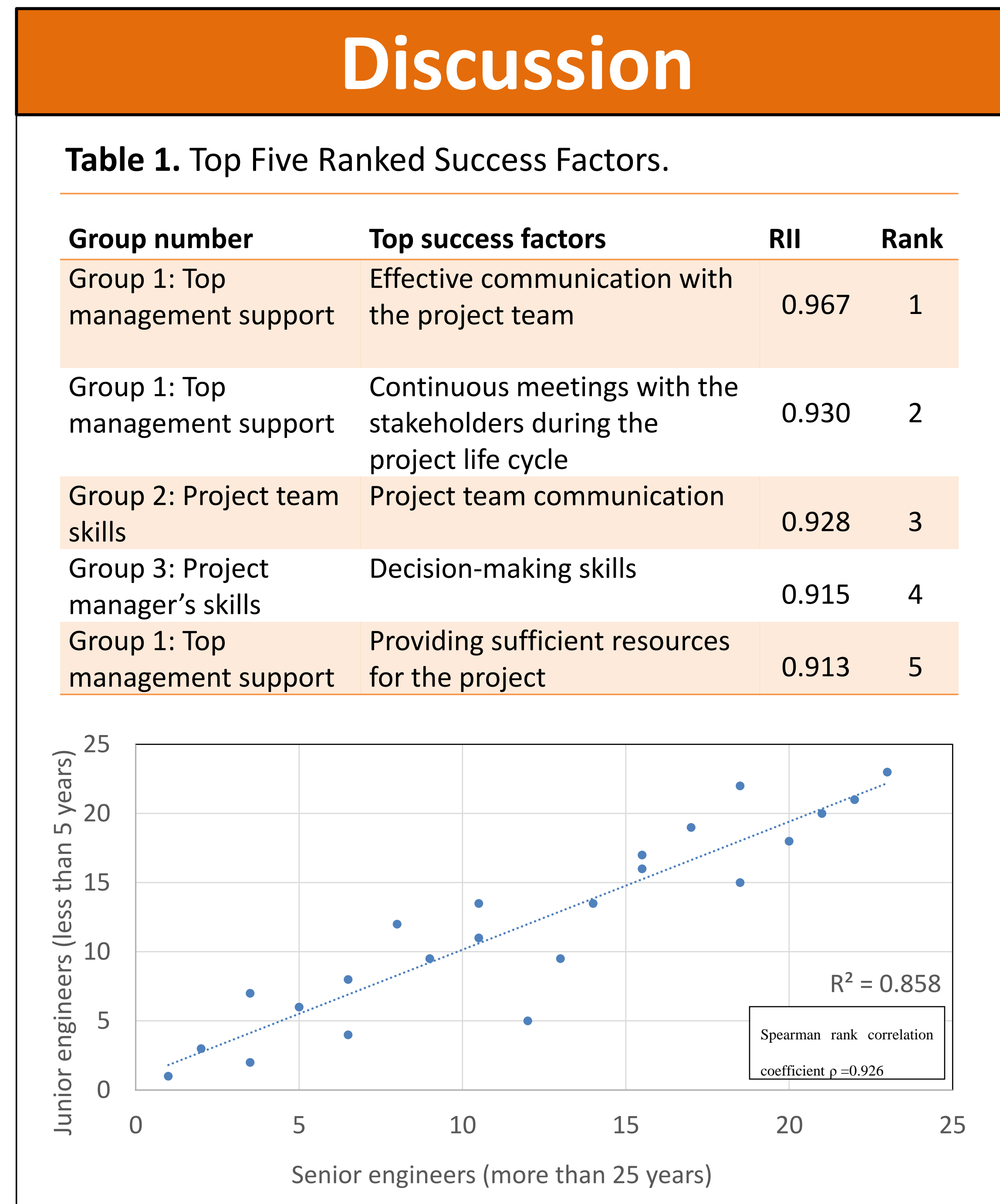

Figure 6. Correlation of the perception of (Junior Vs. Senior Engineers) on the project success factors

Table 2. Top Five Ranked PMKAs.

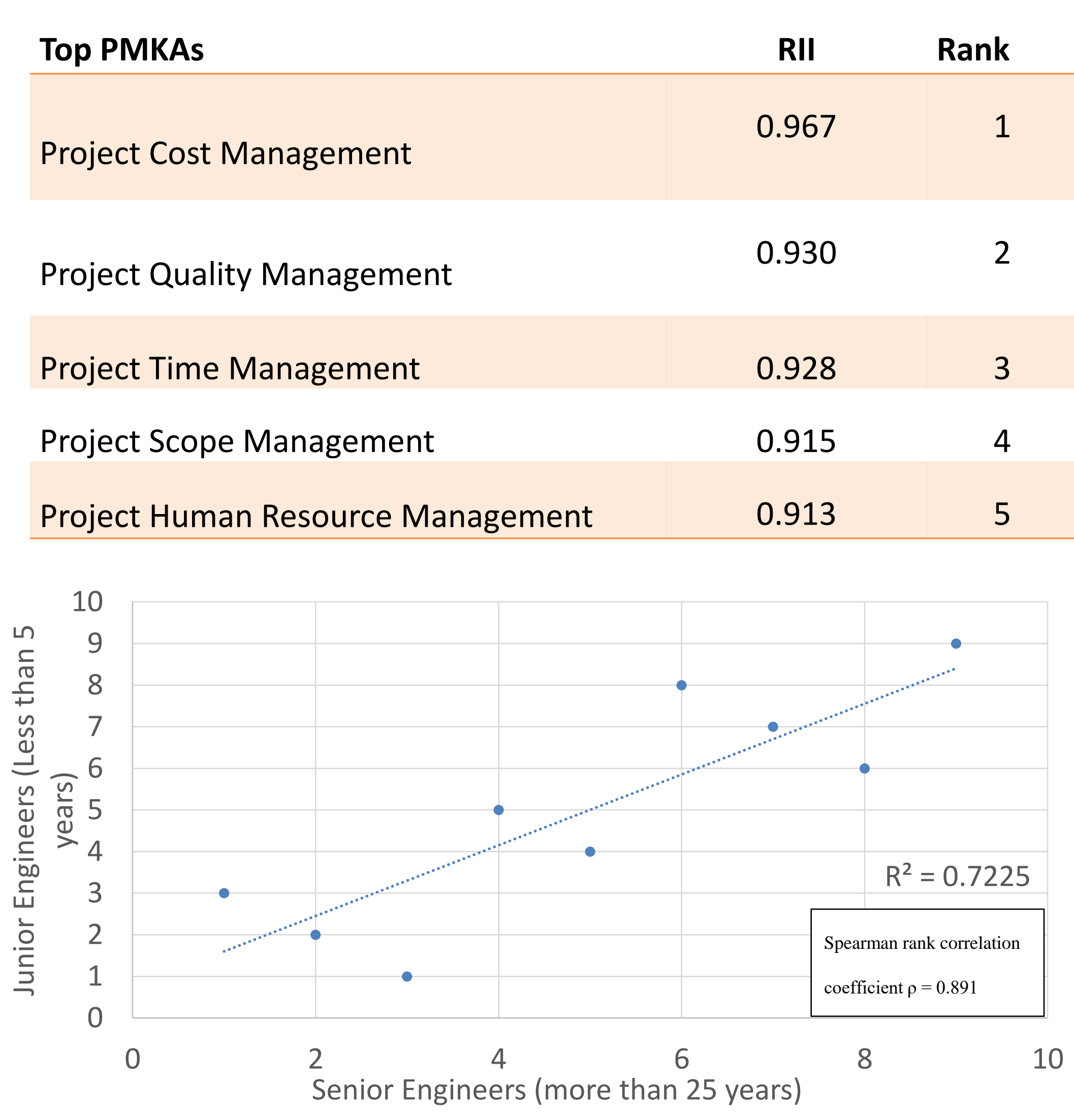

Figure 7. Correlation of the perception of (Junior Vs. Senior Engineers) on the PMKAs

\section{Conclusions}

- All project managers perceive a strong relationship between the factors and the success in construction industry.

- Based on relative ranking, top management support is very important to project success.

- Among the four success criteria, stakeholder's satisfaction is the key for project success.

- Project managers should have all knowledge areas, except procurement, for better project performance.

\section{References}

- Bekr, G. (2017). Factors affecting performance of construction projects in unstable political and economic situations. Journal of Engineering and Applied Sciences, 5384

- Ibrahim, A. \&. (2019). The Influence of Project Management Knowledge of Academics on the Success of University Research Projects. European Journal of Business and Management, 119-132.

Khamaksorn, A. (2018). Project Management Knowledge and Skills for the Construction Industry.

Niagara, P., \& Datche, E. (2015). Factors Affecting the Performance of Construction Projects: A Survey of Construction Projects in the Coastal Region of Kenya. International Journal of Scientific and Research Publications, 2250-3153. 